Western North American Naturalist 69(4), ( 2009, pp. 426-436

\title{
SURVEY INDICATORS FOR PYGMY RABBITS: TEMPORAL TRENDS OF BURROW SYSTEMS AND PELLETS
}

\author{
Dana M. Sanchez ${ }^{1,4}$, Janet L. Rachlow ${ }^{1}$, Andrew P. Robinson²,5, and Timothy R. Johnson ${ }^{3}$
}

\begin{abstract}
Obtaining estimates of absolute abundance for rare or cryptic species can be challenging. In these cases, methods using indirect indicators such as sign might offer useful indices of population size. Pygmy rabbits (Brachylagus idahoensis) are small, burrowing lagomorphs for which methods for population assessment and monitoring are needed. Current tools for estimating relative abundance rely on detecting and assessing fecal pellets and burrow systems. We evaluated temporal changes in each of these indicators to gauge their potential usefulness as indicators of relative and absolute abundance of pygmy rabbits. Pellet persistence was strongly influenced by environmental exposure, and based on our data, we estimated that maximum persistence of fecal pellets would be 24-34 months. Pellet appearance (color) was affected by both time and exposure. Burrow systems were remarkably resilient over the course of the study. Probability of burrow systems transitioning between activity classes (active, recent, and old) did not vary detectably by study site, season, or year. We suggest that 2 protocols currently used for classification of pygmy rabbit burrow systems are most useful for different applications. Further work is needed, however, to link such assessments to quantitative estimates of population size.
\end{abstract}

Key words: pygmy rabbit, Brachylagus idahoensis, survey indicators, pellet persistence, burrow systems, population index, monitoring, Idaho.

Efficient techniques are needed for broadscale surveys of changes in population abundance. Designing such tools is challenging when working with species that are rare or difficult to observe directly, such as semifossorial mammals. In such cases, indirect measures of population abundance, such as the number of species-specific structures or sign, might be used as an index to population abundance. For some species, validated indices can provide reliable estimates of absolute density (e.g., Krebs et al. 1987, 2001). For others, such tools offer a rough standard against which to detect bias in other methods used to estimate population changes (Winterstein et al. 2001) or are best used to infer population trends over time (Biggins et al. 2006). Estimation of population trends is especially important for rare, threatened, or endangered species.

The pygmy rabbit (Brachylagus idahoensis) is a sagebrush- (Artemisia spp.) dependent species for which population estimation tools are needed. The rabbit is the smallest leporid (Wilde 1978), is unique in being 1 of 2 native North American leporids that actively excavate burrow systems (Dobler and Dixon 1990), and is patchily distributed within the sagebrush shrubsteppe. In addition, pygmy rabbits exhibit burrowing behavior, crypticity, and effective use of shrubs for security cover when disturbed by human observers. These characteristics complicate use of population survey methods that rely on direct observation of individual animals. Much of the potential range for the species has been converted to uses such as livestock grazing, dryland agriculture, irrigated agriculture, and residential development (Knick and Rotenberry 2002). These sources of fragmentation, along with expanding energy exploration within the sagebrush ecosystem (Ingelfinger and Anderson 2004), threaten to further fragment and decrease habitat available to the species. Furthermore, after a dramatic decline in remaining populations of free-ranging rabbits in Washington, the Columbia Basin population was listed as an Endangered Distinct Population Segment under the Endangered Species Act (ESA, Hays 2001, United States Fish and Wildlife Service 2003), and the U.S. Fish and Wildlife Service is currently reviewing a petition to list the species as threatened or endangered across its geographic range (United States

\footnotetext{
${ }^{1}$ Department of Fish and Wildlife Resources, College of Natural Resources, Box 441136, University of Idaho, Moscow, ID 83844-1136.

${ }^{2}$ Department of Forest Resources, University of Idaho, Moscow, ID 83844.

${ }^{3}$ Department of Statistics, University of Idaho, Moscow, ID 83844.

${ }^{4}$ Present address: Department of Fisheries and Wildlife, Oregon State University, Nash 104, Corvallis, OR 97331-3803. E-mail: dana.sanchez@oregonstate.edu

5 Present address: Department of Mathematics and Statistics, University of Melbourne, Victoria, VIC3010, Australia.
} 
Fish and Wildlife Service 2008). Although pygmy rabbits can be studied with trapping and radiotelemetry, such efforts require logistical investments that are infeasible at numerous sites over broad spatial extents. Inventory and monitoring efforts are being conducted over these broad geographic extents due in part to the potential change in status and conservation concerns for the species. Therefore, efficient and accurate population survey methods are needed.

Current qualitative methods for assessing relative abundance of pygmy rabbits rely on 2 indicators: burrow systems and fecal pellets. In addition to identifying presence of the species, the appearance and presence of fecal pellets and burrow entrances are used in concert as indicators of the activity status of burrow systems; they can signify whether a burrow system is currently in use, has been used in the recent past, or has been vacant for a considerable period of time. However, multiple factors might affect the persistence and appearance of each of these 2 indicators. Pellet detection depends on pellet persistence and, to some degree, on pellet appearance. Degradation and detectability are affected by age (time) and also by seasonal weather conditions and the degree to which pellets are sheltered from these environmental forces by vegetation cover (e.g., Riney 1957, Cochran and Stains 1961, Wallmo et al. 1962, Flinders and Crawford 1977, Harestad and Bunnell 1987, Palomares 2001). Soil microorganisms, invertebrates, and vertebrates also influence persistence and detectability of feces (e.g., Cochran and Stains 1961, Angel and Wicklow 1974, Harestad and Bunnell 1987, Sanchez et al. 2004). Similarly, temporal trends in persistence and appearance of burrow systems depend on seasonal weather effects on soil that is susceptible to slumping and compaction, on vegetation cover surrounding burrow systems, or on local density of burrow systems.

Protocols for classifying pygmy rabbit burrows that have been applied in Idaho (Roberts 2001) and in Washington (Hays 2004) use both fecal pellets (presence and appearance) and integrity of burrow system entrances as indicators of the activity status of burrow systems. Repeated censuses of burrow systems in an area might provide a qualitative assessment of changes in relative abundance of rabbits over time. For pellets and burrow systems to act as reliable indicators in a quantitative index of animal abundance, however, an understanding of how their characteristics change over time is needed. After this is achieved, and if the number of active burrow systems is responsive to changes in the population, burrow systems might provide a valuable quantitative index of population abundance. Similarly, knowledge of how appearance of burrow systems changes over time would facilitate estimation of time-since-occupancy for currently unoccupied sites.

Our goal was to evaluate the assumptions of burrow classification methods that rely on evaluating pellets and burrow entrances to estimate activity status of burrow systems. Because detecting fecal pellets near burrow system entrances serves as a first step in assessing activity of burrow systems, our first objective was to investigate the potential effects of environmental exposure and time on persistence of pellets. We expected that pellet persistence would decrease over time and that the rate of degradation would be influenced by environmental exposure. Therefore, we predicted that pellets sheltered beneath sagebrush canopy would disappear more slowly than those deposited in the open. When detected, appearance of persisting pellets is used to evaluate current occupancy of a burrow system. Survey methods that use color as an indicator of pellet freshness assume that pellet color changes linearly over time (darker to lighter) and that this progression is independent of other factors, such as environmental exposure. If these assumptions were true, we would expect pellet color to change from darker to lighter over time and that linear change in pellet color would not be reversed by weather events or environmental exposure.

Our second objective was to evaluate assumptions about temporal trends in burrow system complexity (i.e., number of entrances) and activity level (i.e., use of burrows by rabbits). We expected that burrow systems would become more complex as time progressed and that the timing of changes in both complexity and activity level would reflect seasonal variation in precipitation and rabbit reproduction. For example, we expected that new entrances would be excavated and that activity levels would increase during late spring and early summer when moist soils would facilitate digging and when reproduction might increase 
local population densities. We used our analyses of burrow systems and pellets to evaluate protocols currently used by biologists to qualitatively assess populations of pygmy rabbits.

\section{METHODS}

\section{Study Area}

The study area was in the Lemhi Valley $\left(44.680^{\circ} \mathrm{N}, 113.357^{\circ} \mathrm{W}\right)$ in east central Idaho. Study area elevations ranged from $1880 \mathrm{~m}$ to $2050 \mathrm{~m}$ and terrain consisted of alluvial outwash fans and floodplain. Mima mounds, low mounds of earth of uncertain origin (Tullis 1995), occurred across much of the study area and supported the tallest shrub growth. The area was managed by the Bureau of Land Management (BLM) for multiple uses, including big-game and upland-game hunting, furbearer trapping, and seasonal grazing by cattle. Sagebrush specialists such as the Greater SageGrouse (Centrocercus urophasianus) and Sage Sparrow (Amphispiza belli) also were present. In addition to pygmy rabbits, lagomorphs in the area included mountain cottontail rabbits (Sylvilagus nuttallii), white-tailed jackrabbits (Lepus townsendii), and black-tailed jackrabbits (Lepus californicus).

The area was within the western intermountain sagebrush-steppe ecosystem (West 1983). Sagebrush species occurring on the area included Wyoming big sagebrush (Artemisia tridentata ssp. wyomingensis), threetip sagebrush (Artemisia tripartita ssp. tripartata), and black sagebrush (Artemisia nova). The understory included 3 species of rabbitbrush: common or rubber rabbitbrush (Chrysothamnus nauseosus), green rabbitbrush (Chrysothamnus viscidiflorus), and broad-leaved rabbitbrush (Chrysothamnus viscidiflorus var. lanceolatus). Seasonal high and low temperatures collected from 2002 through 2005 at the nearest weather monitoring station (approximately $4 \mathrm{~km}$ from the area) averaged $-0.5{ }^{\circ} \mathrm{C}$ and $-15.2{ }^{\circ} \mathrm{C}$ in winter (December-February), $11.8{ }^{\circ} \mathrm{C}$ and $-3.9{ }^{\circ} \mathrm{C}$ in spring (March-May), $25.9^{\circ} \mathrm{C}$ and $4.1{ }^{\circ} \mathrm{C}$ in summer (June-August), and $12.9{ }^{\circ} \mathrm{C}$ and $-5.5^{\circ} \mathrm{C}$ in autumn (September-November). Seasonal precipitation averaged $0.7 \mathrm{~cm}$ in winter, $1.9 \mathrm{~cm}$ in spring, $2.3 \mathrm{~cm}$ in summer, and $1.3 \mathrm{~cm}$ in autumn (Leadore station, Western Regional Climate Center 2006).

We delineated 2 study sites within the area: Cedar Gulch (CG) and Rocky Canyon (RC).
The CG site (125 ha) featured prominent mima mounds, upon which Wyoming big sagebrush and pygmy rabbit burrow systems were concentrated. Intermound vegetation was sparsely distributed and consisted of low-growing forbs, subshrubs, and grasses. Mima mounds and associated Wyoming big sagebrush also were common on the RC site (120 ha), and intermound vegetation included threetip sagebrush, rabbitbrush, forbs, and grasses.

\section{Persistence of Pellets}

Given the environmental extremes common to sagebrush communities, we expected that environmental exposure might influence degradation rates of pellets. To determine the effect of environmental exposure on persistence of fecal pellets, we established paired plots beneath sagebrush canopy and in exposed sites. We designed quadrat frames to allow weather and small organisms such as insects to act on pellets, while attempting to exclude larger animals, such as rabbits. Rebar tripods (approximately $46 \mathrm{~cm}$ tall, plot area approximately 729 $\mathrm{cm}^{2}$ ) were wrapped with medium-aperture hardware cloth $(5 \times 10$-cm grid). Small-aperture hardware cloth $(1.3 \times 1.3-\mathrm{cm}$ grid $)$ was then wrapped around the lowest $10 \mathrm{~cm}$ of the tripod. Plots were paired by environmental exposure, with the first subplot located beneath sagebrush canopy (sheltered) and the second subplot located in the open space between shrubs (exposed). We collected fresh pellets produced by trapped adult rabbits as well as pellets found opportunistically in burrow entrances immediately following fresh snow during the 2005 breeding season (February-July).

We assigned pellets $(n=20)$ to sheltered and exposed subplots within the replicate stations $(n=18)$. We located stations near individual burrow systems subsampled from those ranked as active or recently active during October 2003. We revisited the stations quarterly (March, June, September, December) as snowcover allowed. We noticed that despite our efforts to the contrary, some subplots were adversely affected by behaviors of pygmy rabbits and possibly other species. Some disturbances to subplots, such as use of the subplot space for dust bathing and deposition of fresh pellets on top of study pellets, apparently resulted when pygmy rabbits succeeded in climbing through the medium-aperture hardware cloth. Other disturbances, such as the 
addition of pellets via dusting or kicking activity in the duff immediately adjacent to the subplot, resulted from the actions of rabbits and other species outside the caged subplots. Pairs for which one subplot was compromised by these types of disturbances were removed from analysis. For the remaining pairs, we calculated the mean proportion of pellets persisting and assessed the potential influences of study site and exposure on pellet persistence. We tested for study site and exposure effects with an analysis of variance (ANOVA) model constructed using PROC GLM in SAS (2001). Proportions were arcsine-transformed for analyses, and we reported mean percent of pellets remaining

\section{Appearance of Pellets}

To determine how color of pellets changed with season, time, and exposure, we used the Munsell color system (Munsell Color 1929, 2000) to quantify exterior color of pellets. The Munsell System of Color Notation is a "color appearance” system (Miller 1958) commonly used by soil scientists and other professionals when an objective, quantifiable method of color description is needed. In the Munsell system, each color is classified as to hue, value, and chroma (expressed as hue value/chroma). Hue indicates the relation to red, yellow, green, blue, and purple. Value gives an indication of lightness or brightness ( 0 for absolute black, 10 for absolute white), and chroma refers to color strength or saturation.

Because pygmy rabbit diets vary by season (Wilde 1978, Green and Flinders 1980), we expected that pellet composition could affect temporal changes in exterior color of pellets. Therefore, we collected fresh pellets produced by trapped adult rabbits and those found opportunistically in burrow entrances immediately following fresh snow during the 2004 breeding (February-July) and nonbreeding (August 2004-January 2005) seasons. To retard drying and aging of pellets collected over the course of a season and to ensure a mixture of pellets from throughout the season, we refrigerated samples until the deployment date. Before setting the pellets out in the environment (Aug 2004, breeding-season pellets; Feb 2005, nonbreeding-season pellets), we recorded Munsell color parameters (hue, value, chroma) of the darkest dominant exterior color for each pellet. Paired subplots $(11.5 \times 11.5 \mathrm{~cm})$ were delineated with wooden sticks and located in areas of sagebrush shrubsteppe without pygmy rabbits, who might otherwise hamper efforts to isolate the pellets. We placed 14 breeding-season pellets in each subplot (exposed and sheltered) of 1 station. We constructed 3 nonbreeding-season stations with paired subplots (13 pellets per subplot). We periodically recorded Munsell color parameters for persisting pellets at intervals of 1-3 months for 1 year.

Within each season, we tested for main effects of time and exposure during one year of observations for each type of pellet (breeding, 7 periods; nonbreeding, 6 periods). We analyzed data with 2-way multivariate analysis of variance (MANOVA) and associated canonical analyses in SAS (2001).

\section{Census of Burrow Systems}

To determine how burrow systems changed over time, we initially censused and mapped burrow systems of pygmy rabbits on the CG and RC study sites in October 2003. Census workers extensively searched belt transects covering the CG and RC sites. We used global positioning system (GPS) units to record the location of each burrow system. We recorded the number of entrances and activity state for every burrow system. When counting entrances, we considered only those with diameters $\geq 7$ $\mathrm{cm}$ to be associated with pygmy rabbit activity. We used a protocol developed in Idaho (Roberts 2001; Table 1) for classifying activity state of burrow systems based on presence of fecal pellets, estimated age of fecal pellets, and condition of burrow entrances. Glossiness and exterior color of fecal pellets were used to categorize age as "recent" or "old." Pellets with damp interiors or glossy exteriors were interpreted as being fresh or recent. Pellets that lacked exterior glossiness but exhibited rich green or brown hues also were considered fresh. Pellets with beige, yellow, and gray exterior colors were classified as old.

Integrity of burrow entrances and accumulation of debris also determined the assignment of activity status to burrow systems (Table 1). Burrow systems with multiple entrances were assigned a rank based on the entrance that warranted the highest activity classification. In ambiguous cases, we allowed pellets to outrank other indicators. For example, the presence of old pellets at a burrow system with an entrance that was occluded by litter and showed no 
TABLE 1. Two classification protocols currently used for estimating activity levels of pygmy rabbit burrow systems based on sign and integrity of burrow entrances. Criteria were adapted from protocols developed for use in Idaho (Roberts 2001) and Washington (Hays 2004). We modified the Idaho system to a 2-category classification by combining the active and recent classes into a "used" class and by combining the old and very old classes into an "unused" class.

\begin{tabular}{|c|c|c|c|}
\hline $\begin{array}{l}\text { Burrow system and } \\
\text { activity class }\end{array}$ & Integrity of entrance $(\mathrm{s})$ & Pellet characteristics & Evidence of recent excavation \\
\hline \multicolumn{4}{|l|}{ Idaho } \\
\hline Active & entrance open and intact & fresh pellets present & fresh diggings evident/abundant ${ }^{\mathrm{a}}$ \\
\hline Recent & entrance open and intact & old/weathered pellets present & diggings old, few, or absent \\
\hline Old & $\begin{array}{l}\text { entrance open and intact } \\
\text { or slightly debris-obstructed }\end{array}$ & pellets absent & diggings old, few, or absent \\
\hline Very old & entrance collapsed ${ }^{\mathrm{b}}$ & pellets absent & diggings old, few, or absent \\
\hline \multicolumn{4}{|l|}{ Washington } \\
\hline Active & entrance open and intact & fresh pellets present & fresh diggings evident/abundant \\
\hline Inactive & $\begin{array}{l}\text { entrance open and intact } \\
\text { or slightly debris-obstructed }\end{array}$ & old/weathered pellets present & \\
\hline Historic & $\begin{array}{l}\text { entrance open and intact } \\
\text { or slightly debris-obstructed } \\
\text { or collapsed }\end{array}$ & old/weathered pellets present & \\
\hline
\end{tabular}

atetection of fresh pellets resulted in an "active" ranking, regardless of excavation evidence.

bCollapsed openings were only considered to be a burrow system entrance if the top half of the arch remained identifiable as an opening likely to have been associated with pygmy rabbit use.

evidence of fresh digging would be classified as recent, rather than old, based on the presence of pellets (Table 1).

\section{Activity Status of Burrow Systems}

To determine how activity status of burrow systems varied by season and between sites, we tracked quarterly changes in activity status of a subsample of burrow systems mapped during the 2003 census of burrow systems. We first stratified the censused burrow systems by study site (CG, RC) and then by (Idaho system) activity level (active, recent, or old; Table 1) within each site. Within the 6 strata (active, recent, and old within each of the 2 areas) we sorted the burrow systems by number of entrances. For each of the 6 strata, we then selected a random start point within the sorted list and systematically selected 10 burrows. This resulted in a total sample size of 60 burrow systems. We did not include "very old" burrow systems in our stratification or subsequent analyses because of wide variability within the class as to condition and the confidence with which we could positively identify the burrows as having been occupied by pygmy rabbits.

Beginning in March 2004, we recorded activity status of each of the 60 burrow systems quarterly during 2004 and 2005 (March, June, and September in both years; December 2004). We recorded activity status of burrow systems using both the Idaho and Washington protocols (Table 1) because both systems are currently used in the field and each relies in part on changes in pellet persistence and appearance for determinations of burrow status. Burrow systems that were degraded beyond the criteria for a "very old" ranking in the Idaho protocol and the "historic" ranking in the Washington protocol were recorded as "not ranked."

We used data collected under the Idaho protocol in our detailed analysis of changes in activity status of burrow systems. We defined seasons as the intervals between visits: January-March (winter), April-June (spring), July-September (summer), and October-December (fall). Snowcover during December 2004 prevented assessment of 18 burrow systems on RC. We considered 2 scenarios based on data from the intervals preceding and following the missing observation for those 18 burrow systems. In the first case we assumed that no change had occurred during the interval. We then considered the converse and assumed that a change had occurred.

We evaluated potential annual, seasonal, and site effects on quarterly changes in activity status of burrow systems using a generalized mixed-effects model (GLMM using the lme4 package of the open-source statistical environment R; Bates 2007, R Development Core Team 2007). We reclassified the burrow activity data into a 2-category classification to allow for potential environmental biases in pelletaging decisions and to distill the data into a 
more biologically meaningful framework. We combined the active and recent activity classes of the Idaho protocol into a "used" class, while the old, collapsed, and "not ranked" categories were combined into an "unused" class (Table 1). The resulting dichotomous system thus classified burrows into those that had dependable evidence of recent pygmy rabbit activity and those that did not. The response variable was the change in status $(1=$ change, $0=$ no change) by individual burrow systems, which we connected to the candidate explanatory variables (i.e., annual, seasonal, and site) via a logit link function. We wished to allow for the possibility that any burrow might have a propensity for change or stability that could not be captured by our candidate explanatory variables, so we assigned a random effect to each burrow. We tested for statistical significance and summarized the results by using the highest posterior-density intervals of Markov Chain Monte-Carlo simulations to estimate an approximate ANOVA table for the main effects.

\section{Complexity of Burrow Systems}

To discover how complexity of burrow systems varied between seasons and sites, we also tracked quarterly changes in the complexity, or number of entrances, by each of the 60 burrow systems for which we were documenting activity levels. We used change in entrance counts as our response variable. We censored those burrow systems $(n=14)$ that never changed in complexity over the course of our study. We tested for effects of season and study site on quarterly changes in complexity of individual burrow systems using a linear mixed-effects model.

\section{REsUlts}

\section{Persistence and Appearance of Pellets}

Environmental exposure strongly influenced pellet persistence and might therefore influence surveys relying on detection of pellets. We were able to retain and analyze data from 11 plot pairs (CG, $n=5$; RC, $n=6$ ). At both study sites, pellets sheltered beneath shrub canopy persisted longer than those exposed in the open between shrubs $(F=9.60, P=0.003)$; however, the influence of exposure varied between the 2 sites (study site $\times$ treatment interaction, $F=7.06, P=0.010)$. Combined across sites, we estimated that maximum per- sistence of exposed pellets was 24 months (arcsine-transformed proportion remaining $=$ $1.37-0.06$ time), and that maximum persistence of sheltered pellets was 34 months (arcsine-transformed proportion remaining $=1.51$ -0.04 time).

Initial average color of fresh pellets from the nonbreeding season was somewhat lighter than pellets collected during the breeding season (Table 2). Although initial pellet color differed by season, changes in exterior color of all pellets were influenced by multiple factors. Both exposure and time influenced color of breeding season pellets (exposure: Wilks' $\lambda=$ $0.73 ; \mathrm{df}=3,175 ; P<0.001$ ) (time: Wilks' $\lambda=$ $0.51 ; \mathrm{df}=18,496 ; P<0.001)$. Exterior color of nonbreeding season pellets was similarly influenced by both exposure and time (exposure: Wilks' $\lambda=9.1 ; \mathrm{df}=3,330 ; P<0.001)$ (time: Wilks' $\lambda=18.81$; $\mathrm{df}=15,911 ; P<$ 0.001). For all pellets, the value (brightness) of pellet color was greatly increased by exposure, whereas value increased over time, and hue (overall color) also was influenced by time. For example, a dark brown pellet would become more beige (increase in value) if exposed but remain relatively dark if sheltered.

\section{Activity and Complexity of Burrow Systems}

During the burrow census in October 2003, we mapped and recorded number of entrances and activity status for a total of 845 burrow systems at 2 study sites. At the CG site, we classified 134, 36, 38, and 38 burrow systems in the active, recent, old, and "very old" activity categories, respectively. Density of burrow systems classified in the active and recent categories was 1.36 burrow systems $\cdot \mathrm{ha}^{-1}$ on the CG site. On the RC site, we classified 249, 107, 123 , and 119 burrow systems as active, recent, old, and very old, respectively. Burrow systems categorized into the 2 most active categories (active and recent) occurred at a density of 3.06 burrow systems $\cdot \mathrm{ha}^{-1}$ on the RC site.

Under the simplified Idaho system, burrow systems did not vary greatly in activity level over time. More than half of the burrow systems $(n=39)$ did not change in activity level over the course of 24 months (October 2003-September 2005). Among those burrow systems that changed $(n=21)$, we found no evidence of significant annual $(\mathrm{df}=1$, sum of squares $[\mathrm{SS}]=$ $0.18, P=0.737)$, seasonal $(\mathrm{df}=3, \mathrm{SS}=0.97, P$ $=0.662$; Table 3$)$, or study site-specific $(\mathrm{df}=1$, 
TABLE 2. Temporal changes in median exterior color of pygmy rabbit fecal pellets over one year (2004) for pellets collected during the breeding and nonbreeding seasons in the Lemhi Valley, Idaho. Color chips were scanned from the Munsell Soil Color Charts $\S$ (Munsell Color 2000). Photos courtesy of X-Rite, Incorporated.

\begin{tabular}{|c|c|c|c|c|c|}
\hline \multicolumn{3}{|c|}{ Breeding season pellets } & \multicolumn{3}{|c|}{ Non-breeding season pellets } \\
\hline Time & Exposed & Sheltered & Time & Exposed & Sheltered \\
\hline August 2004 & & $\mathrm{~b}$ & Feb 2005 & & $\mathrm{c}$ \\
\hline Sep 2004 & & & & & \\
\hline Oct 2004 & $f$ & g & Apr 2005 & $\mathrm{~h}$ & $\mathrm{c}$ \\
\hline Dec 2004 & & $\mathrm{i}$ & & & \\
\hline Jan 2005 & $\mathrm{j}$ & i & Jul 2005 & & f \\
\hline Feb 2005 & $\mathrm{j}$ & $\mathrm{d}$ & Oct 2005 & i & $\mathrm{c}$ \\
\hline Apr 2005 & l & $c^{*}$ & Dec 2005 & $\mathrm{~m}$ & $\mathrm{c}$ \\
\hline Jul 2005 & c & $\mathrm{c}$ & Feb 2005 & 1 & \\
\hline
\end{tabular}

\$Color names and Munsell notations (hue value/chroma) were as follows: (a) very dark gray (10YR 3/1.5), (b) very dark gray (10YR 3/1), (c) dark grayish brown (10YR 4/2), (d) very dark grayish brown (10YR 3/2), (e) very dark gray (7.5YR 3/1.5), (f) brown (7.5YR 4/2), (g) very dark gray (5YR 3/1), (h) brown (10YR 4/3), (i) dark brown (7.5YR 3/2), (j) dark reddish gray (5YR 4/2), (k) brown (7.5YR 5/2), (1) grayish brown (10YR 5/2), (m) grayish brown (2.5Y 5/2), and (n) gray (10YR $4.5 / 1$.

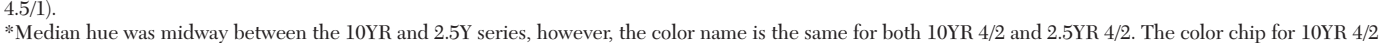
is shown.

TABLE 3. Frequency of quarterly changes in activity status and complexity of burrow systems of pygmy rabbits monitored October 2003-September 2005 in the Lemhi Valley, Idaho. Sample size $(n)$ for activity status reflects the number of observations obtained during seasonal intervals (e.g., only one Fall interval), censoring of those burrow systems that were classified as not ranked within the interval, and weather-related reductions in sampling (fall interval). Sample size ( $n$ ) for complexity reflects weather-related reductions in sampling (fall interval).

\begin{tabular}{|c|c|c|c|c|c|c|c|c|}
\hline & \multicolumn{2}{|c|}{ Spring } & \multicolumn{2}{|c|}{ Summer } & \multicolumn{2}{|c|}{ Fall } & \multicolumn{2}{|c|}{ Winter } \\
\hline & $n$ & $\%$ & $n$ & $\%$ & $n$ & $\%$ & $n$ & $\%$ \\
\hline \multicolumn{9}{|l|}{ Activity status } \\
\hline No change & 99 & 0.92 & 94 & 0.89 & 34 & 0.87 & 82 & 0.88 \\
\hline Changed & 9 & 0.08 & 12 & 0.11 & 5 & 0.13 & 11 & 0.12 \\
\hline \multicolumn{9}{|l|}{ Complexity } \\
\hline Decreased & 21 & 0.18 & 20 & 0.17 & 2 & 0.05 & 20 & 0.20 \\
\hline No change & 88 & 0.73 & 89 & 0.74 & 33 & 0.79 & 69 & 0.68 \\
\hline Increased & 11 & 0.09 & 11 & 0.09 & 7 & 0.17 & 13 & 0.13 \\
\hline
\end{tabular}

SS $=0.27, P=0.199)$ influences on changes in burrow system activity. Similarly, activity status in the preceding quarter did not significantly affect status in the following quarter $(\mathrm{df}=1$, SS $=0.07, P=0.479$ ), nor did preceding status interact significantly with season $(P=0.479)$ or study site $(P=0.237)$ to effect change in burrow system activity.
The Idaho and Washington classification protocols differed in the number of burrow systems that degraded below minimum classification thresholds. The difference resulted from the requirement under the Washington protocol that pellets be present for a burrow system to be ranked. Thirteen burrow systems $(22 \%)$ degraded to a "not ranked" status under 
the Idaho system at least once over the study period. Six burrow systems (10\%) degraded to that status and remained so through the end of the study. Over the same period, $36(60 \%)$ burrow systems degraded to a "not ranked" status at least once under the Washington system. Under that system, 24 burrow systems (40\%) degraded to and then remained in the "not ranked" category.

Many $(n=14)$ burrow systems did not change in number of entrances over the course of our study and were withheld from further analysis of burrow complexity. Among those that changed in complexity $(n=46)$, the probability of changes in burrow system complexity varied neither by study site $(F=0.03, P=0.870)$ nor by season $(F=1.82, P=0.140$; Table 3$)$.

\section{Discussion}

Next to actual sightings of pygmy rabbits, the combination of pellets and burrow systems provides the most reliable evidence of species presence in an area, and together these sign might provide an indirect index of population trends. However, because of temporal trends and environmental exposure, the relative usefulness of pellets and burrow systems as indicators of population trends depends primarily on investigator objectives.

Multiple factors affected temporal changes in pellets. Pellet longevity has important implications both for species-detection efforts and for surveys conducted to estimate population abundance. Pellet longevity was affected by exposure, but the influence of exposure varied between sites. Future investigators should test for site-specific differences in rates of pellet persistence, as these differences affect the temporal sensitivity of pellet-based survey tools.

Pellets from desert cottontail rabbits (Sylvilagus audubonii) and black-tailed jackrabbits in Texas were estimated to require 4.4 and 9.5 years to degrade, respectively (Flinders and Crawford 1977). However, the small size of pygmy rabbit pellets and weather extremes common to the shrubsteppe likely contributed to the shorter persistence times that we observed. In addition to our observations of pellet persistence, the frequency of burrow system transitions into the "not ranked" status under the Washington protocol during our 24month study period supports our estimates of average and maximum persistence by pellets.
Furthermore, these estimates allowed us to calibrate the minimum time-since-occupancy of burrow systems without pellets as ranging from 12 months to as long as 24-34 months. These values likely underestimate the minimum time-since-occupancy, however, because detectability of pellets likely declines as degradation proceeds and as shrub cover increases. Thatch ants (Formica obscuripes), a species that gathers and hoards organic matter, including pygmy rabbit pellets, occurred on our study area (Hedlund 2003). These and other invertebrates might have a significant influence on availability of pellets for detection and sampling near burrow systems.

Unlike our experimental plots, accumulations of pygmy rabbit pellets can form literal "carpets" near some burrow systems. Such situations would likely result in longer persistence times through microclimate conditions within the accumulated mats of pellets. For example, Wik (2002) documented that decay rates of single droppings from Greater Sage-Grouse did not differ among 3 vegetation communities, but piled groups of droppings decayed more slowly in low sagebrush (A. arbuscula) settings. Decay rates of other lagomorph pellets were affected by diet, season, and vegetation cover and type (e.g., eastern cottontail [Sylvilagus floridanus]_Cochran and Stains 1961; snowshoe hare [Lepus americanus] Prugh and Krebs 2004). Thus, future investigators will need to consider both the group size (i.e., number of pellets) and site-specific cover conditions in survey designs.

Exterior appearance of persisting pellets is used as another indicator of how recently a burrow system was occupied. Surveyors typically use "glossiness" as an indicator of acute freshness. Other investigators documented that glossiness was not a consistently reliable indicator of age (Prugh and Krebs 2004). We did not attempt to quantify temporal changes in glossiness. However, if weekly or monthly changes in burrow use are of interest, future research could estimate how long pygmy rabbit pellets retain their "fresh" appearance and whether glossiness is a reliable indicator of pellet age in shrubsteppe environments.

After an initial assessment of pellet dampness or glossiness, color is used to estimate pellet age. Differences in initial color of fresh pellets were likely caused by seasonal differences in rabbit diets. Diets during the breeding 
season include substantial amounts of grasses and forbs, whereas during the nonbreeding season, diets consist of almost exclusively sagebrush (Green and Flinders 1980, Thines et al. 2004). The change in pellet coloration over time was complex. The brightness (value) was greatly increased by exposure, whereas time contributed to changes in both overall color (hue) and brightness (value) within those colors. For example, a dark brown pellet would become more beige (increase in value) if exposed but remain relatively dark if sheltered. Complications arise when the passage of time simultaneously influenced both value and underlying base hue. Exposure also produced changes in chroma, or color saturation. For example, in addition to affecting the value (dark brown vs. beige) of a pellet, exposure also affected the saturation (deep brownness vs. reddish brownness) of the pellet. Therefore, pellets set out at the same time changed colors at different rates, depending on whether they were beneath shrub cover or in the open. This could result in a common color being exhibited by 2 pellets exposed for different lengths of time under different exposure conditions.

Refrigeration of pellets might have contributed to the relatively dark color of pellets when deployed, but prerefrigeration color was not estimated. At a coarse temporal scale, we noted that pellet color changed in an intuitive manner: pellets gradually faded from darker colors to lighter colors. However, at a finer temporal scale, pellet colors sometimes changed in the opposite manner, potentially due to precipitation. If an older pellet displayed a color typical of a fresher sample, a surveyor could mistakenly classify a burrow system at a higher activity level than actually warranted. Surveyors could potentially alleviate the influence of such short-term precipitation effects on pellet appearance by using a simplified, 2-class version of the Idaho protocol or by using the Washington protocol, if the survey is meant to be sensitive at a 1- or 2-year temporal scale. Alternatively, surveys with monitoring at an intermediate temporal scale (seasons to one year) might benefit from use of other estimates of pellet age, such as interior color and moisture.

The burrow systems themselves were surprisingly resilient and stable during our study period. Transitions in burrow system activity did not vary significantly between our 2 study sites, suggesting that ranking tools such as the
Idaho protocol might have wider regional applicability. Although we found annual and site-specific differences in vegetation over a relatively fine spatial scale, shrub canopy and ground cover did not reflect past burrow system activity or duration of occupancy over a coarse temporal scale. Wilde (1978) noted that most alterations to existing burrow systems occurred in June and September, and we had expected that declines in number of entrances would occur during the winter, when wet soil conditions might contribute to tunnel collapse. However, we found no significant seasonal differences in the complexity or activity level of burrow systems. This might have been a result of limited sample sizes. Alternatively, the longevity of pellets, which are used as an indicator of activity status, might mean that these ranking systems are relatively insensitive to seasonal changes.

Estimation of pellet longevity allowed us to evaluate the temporal sensitivity of both classification systems. Based on our estimates, we would expect that a maximum of 2.8 years of inactivity could elapse before a burrow system degraded from the recent to the old activity category in the Idaho system. The same estimate implies that all burrow systems meeting minimum ranking criteria under the Washington system would have been occupied within a similar time frame.

Current tools for estimation of activity of burrow systems provide investigators with useful choices for qualitative assessment of pygmy rabbit populations, but further work is needed to link such assessments to quantitative estimates of population size. Because the longevity of pellets limits the temporal sensitivity of protocols that rank burrow systems, such protocols are most likely to be useful for annual rather than seasonal intervals.

\section{Management Implications}

We suggest that both the Idaho and Washington protocols for classifying burrow systems are useful tools for certain applications. We expected that our strict interpretation of the Washington system as to the presence of pellets might result in a high number of burrow systems reduced to a "not ranked" status in comparison to that resulting from use of the Idaho protocol. Our results confirmed this and thus suggest a useful standard by which to choose the appropriate survey tool. Because 
the Washington protocol ranks only those burrow systems with identifiable pellets of pygmy rabbits, it might be the best tool to use in lowdensity populations. The Washington system precludes false positives for species presence where holes or burrows exist without confirming evidence in the form of pellets. Linkage of this system to a local estimation of average pellet persistence would allow comparisons of confirmed presence (abundance or density of ranked burrow systems) over longer betweensurvey intervals.

The Idaho protocol would provide an investigator with a finer description of qualitative changes in population activity because it incorporates more detail in the characteristics of the pellets being used to estimate burrow status. However multiple, potentially interacting factors complicate changes to the exterior color of pellets. Thus the power of the Idaho system to track temporally fine-scale changes in burrow status would benefit from further work to estimate the persistence of pellet glossiness. If linked to such an estimate, the Idaho protocol would then enable a researcher to identify changes in use of individual burrow systems at a very fine temporal scale.

Because detecting pellets is important to both systems, surveys are best done when the ground is snow-free. However, if confirmation of species presence is the primary goal, moderate snowcover provides major benefits. During moderate snowcover, rabbits tend to remain near burrow entrances, fresh pellets are more obvious on the surface of the snow, and snow trails between burrow entrances help searchers to locate active burrow systems. Further work to calibrate the current survey tools to detect changes in population abundance might allow managers to derive quantitative population estimates for pygmy rabbits from indirect sign such as pellets and burrow systems. However, the survey tools offer investigators opportunities to address important monitoring questions.

\section{ACKNOWLEDGMENTS}

Thanks to J. Witham for his extensive assistance with burrow surveys and other aspects of the project. Thanks to W.A. Estes-Zumpf, B. Waterbury, V. Guyer, and numerous volunteers from Idaho Bureau of Land Management, Montana Bureau of Land Management, Idaho Department of Fish and Game, University of
Idaho, and the United States Forest Service, for their help with burrow censuses. The Leadore Ranger District, especially D. Hilliard, M. Steck, and R. Riebe, provided vital logistic support and housing. The Salmon Field Office of the Bureau of Land Management provided essential funding and logistic support, as did Idaho Department of Fish and Game State Wildlife Grants. K. Steinhorst provided valuable guidance regarding analysis of pellet and vegetation data. D. Sanchez was funded by the Office of the President, University of Idaho, during 2002-2005.

\section{Literature Cited}

ANGEL, K., AND D.T. WiCKLOW. 1974. Decomposition of rabbit faeces: an indication of the significance of the coprophilous microflora in energy flow schemes. Journal of Ecology 62:429-432.

BATES, D. 2007. Lme4: linear mixed-effects models using S4 classes. $\mathrm{R}$ package version $0.99875-9$.

Biggins, D.E., J.G. Sidle, D.B. Seery, and A.E. Ernst. 2006. Estimating the abundance of prairie dogs. Pages 94-107 in J.L. Hoogland, editor. Conservation of the black-tailed prairie dog: saving North America's western grasslands. Island Press, Washington, DC.

Cochran, G.A., and H.J. Stains. 1961. Deposition and decomposition of fecal pellets by cottontails. Journal of Wildlife Management 25:432-435.

Dobler, F.C., And K.R. Dixon. 1990. The pygmy rabbit Brachylagus idahoensis. Pages 111-115 in J.A. Chapman and J.E.C. Flux, editors. Rabbits, hares, and pikas: status survey and conservation action plan. IUCN/SSC Lagomorph Specialist Group, Gland, Switzerland.

Flinders, J.T., AND J.A. Crawford. 1977. Composition and degradation of jackrabbit and cottontail fecal pellets, Texas High Plains. Journal of Range Management 30:217-220.

Green, J.S., AND J.T. Flinders. 1980. Habitat and dietary relationships of the pygmy rabbit. Journal of Range Management 33:136-142.

Harestad, A.S., and F.L. Bunnell. 1987. Persistence of black-tailed deer fecal pellets in coastal habitats. Journal of Wildlife Management 51:33-37.

HaYs, D.W. 2001. Washington pygmy rabbit emergency action plan for species survival. Wildlife Management Program, Washington Department of Fish and Wildlife, Olympia.

2004. Pygmy rabbit survey methods. Washington Department of Fish and Wildlife, Olympia.

Hedlund, K.S. 2003. Online Catalog of Ants of North America. University of North Carolina, Chapel Hill. Available from: http://www.cs.unc.edu/ hedlund/dev /ants/GenusPages/Formacina [accessed 27 October 2003].

Ingelfinger, F., And S.H. Anderson. 2004. Passerine response to roads associated with natural gas extraction in a sagebrush steppe habitat. Western North American Naturalist 64:385-395.

KniCK, S.T., And J.T. Rotenberry. 2002. Effects of habitat fragmentation on passerine birds breeding in 
intermountain shrubsteppe. Studies in Avian Biology 25: 131-141.

Krebs, C.J., R. Boonstra, V. Nams, M. O’Donoghue, K.E. HodGES, AND S. Boutin. 2001. Estimating snowshoe hare population density from pellet plots: a further evaluation. Canadian Journal of Zoology 79:1-4.

Krebs, C.J., B.S. Gilbert, S. Boutin, and R. Boonstra. 1987. Estimation of snowshoe hare population density from turd transects. Canadian Journal of Zoology 65:565-567.

MiLLER, R.S. 1958. The Munsell system of color notation. Journal of Mammalogy 39:278-286.

MunSELl COLOR. 1929. Munsell book of color: a revision and extension of "The Atlas of the Munsell Color System." Munsell Color Company, Baltimore, MD.

Munsell Color. 2000. Munsell soil color charts. Revised edition. Macbeth Division of Kollmorgen Instruments Corporation, New Windsor, NY.

Palomares, F. 2001. Comparison of 3 methods to estimate rabbit abundance in a Mediterranean environment. Wildlife Society Bulletin 29:578-585.

Prugh, L.R., AND C.J. KREBS. 2004. Snowshoe hare pelletdecay rates and aging in different habitats. Wildlife Society Bulletin 32:386-393.

R Development Core Team. 2007. R: a language and environment for statistical computing. R Foundation for Statistical Computing, Vienna, Austria.

RinEY, T. 1957. The use of faeces counts in studies of several free-ranging mammals in New Zealand. New Zealand Journal of Science and Technology 38B: $507-532$.

RoberTs, H.B. 2001. Survey of pygmy rabbit distribution, numbers and habitat use in Lemhi and Custer counties, Idaho. Technical Bulletin 01-11, Idaho Bureau of Land Management, Boise.

Sanchez, D.M., P.R. Krausman, T.R. Livingston, and P.S. Gipson. 2004. Persistence of carnivore scat in the Sonoran Desert. Wildlife Society Bulletin 32: 366-372.

SAS. 2001. SAS, version 8.2. SAS Institute, Inc., Cary, NC.

Thines, N.J., L.A. SHIPLeY, AND R.D. SAYLER. 2004. Effects of cattle grazing on ecology and habitat of Columbia
Basin pygmy rabbits (Brachylagus idahoensis). Biological Conservation 119:525-534.

Tullis, J.A. 1995. Characteristics and origin of earthmounds on the eastern Snake River Plain, Idaho. Master's thesis, Idaho State University, Boise.

United States Fish and Wildlife Service. 2003. Endangered and threatened wildlife and plants; final rule to list the Columbia Basin distinct population segment of the pygmy rabbit (Brachylagus idahoensis) as endangered. Federal Register 68:10388-10409.

2008. Endangered and threatened animals and plants: 90-day finding on a petition to list the pygmy rabbit (Brachylagus idahoensis) as threatened or endangered. Federal Register 73:1312-1313.

Wallmo, O.C., A.W. JaCKSON, T.L. Hailey and R.L. CARLISLE. 1962. Influence of rain on the count of deer pellet groups. Journal of Wildlife Management 26:50-55.

WEst, N.E. 1983. Western intermountain sagebrush steppe. Pages 351-374 in N.E. West, editor, Temperate deserts and semi-deserts. Elsevier Scientific Publishing, New York.

Western Regional Climate Center. 2006. Period of record monthly climate summary for Leadore 2, Idaho (105177). Available from: http://www.wrcc.dri .edu [accessed 23 January 2006].

WIK, P.A. 2002. Ecology of Greater Sage-Grouse in southcentral Owyhee County, Idaho. Master's thesis, University of Idaho, Moscow.

WiLDE, D.B. 1978. A population analysis of the pygmy rabbit (Sylvilagus idahoensis) on the INEL site. Doctoral dissertation, Idaho State University, Boise.

Winterstein, S.R., K.H. POllock, and C.M. Bunck. 2001. Analysis of survival data from radiotelemetry studies. Pages 351-380 in J.J. Millspaugh, and J.M. Marzluff, editors, Radio tracking and animal populations. Academic Press, San Diego, CA.

Received 27 February 2008 Accepted 1 July 2009 